\title{
Global mapping of RNA G-quadruplexes (G4-RNAs) using G4RP-seq
}

\author{
Sunny Y. Yang ${ }^{1}$, David Monchaud ${ }^{2}$, \& Judy M.Y. Wong ${ }^{1 / *}$
}

${ }^{1}$ Faculty of Pharmaceutical Sciences, University of British Columbia, Pharmaceutical Sciences Building, 2405 Wesbrook Mall, V6T 1Z3, Vancouver, Canada

${ }^{2}$ Institut de Chimie Moléculaire, ICMUB CNRS UMR 6302, UBFC Dijon, France

*correspondence: Dr. Judy Wong; Tel: 604-827-3314; Fax: 604-822-3035; Email: judy.wong@ubc.ca EDITORIAL SUMMARY Guanine-rich RNAs folded into G-quadruplex structures (G4-RNAs) are captured from crosslinked RNA using a G4-specific chemical probe, BioTASQ, and mapped globally by sequencing.

PROPOSED TWEET \#NewNProt for capturing RNA G-quadruplexes (G4-RNAs) using a G4-specific probe. @dmonchaud

PROPOSED TEASER Global mapping of G4 RNAS

\section{Related links}

Key reference(s) using this protocol

Yang, S. et al. Nat Commun 9, 4730 (2018): https://doi.org/10.1038/s41467-018-07224-8

Renard, I. et al. Nucleic Acids Research 47, 5502-5510 (2019): https://doi.org/10.1093/nar/gkz215 
Guanine-rich RNAs can fold into four-stranded structures, termed G-quadruplexes (G4-RNAs), and participate in a wide range of biological processes. Here, we describe in detail the G4-RNA-specific precipitation (G4RP) protocol, which allows the transcriptomic profiling of G4-RNAs. The G4RP protocol consists of a chemical crosslinking step, followed by affinity capture with the G4-specific probe, BioTASQ. G4RP can be coupled with sequencing to capture a comprehensive global snapshot of folded

7 G4-RNAs. This method can also be used to profile induced changes (i.e. through G4 ligand treatments) within the G4-RNA transcriptome. The entire protocol can be completed in 1-2 weeks and can be scaled up or down depending on the specific experimental goals. In addition to the protocol details, we also provide here a guide for optimization in different laboratory setups.

\section{INTRODUCTION}

13 G-quadruplexes (G4s) are non-canonical nucleic acid structures formed by Hoogsteen bonding of four 14 guanines to form planar guanine quartet (G-quartet) units, which $\pi$-stack on each other to form the 15 overall columnar structure ${ }^{1-2}$. G4s forming in DNAs (G4-DNAs) ${ }^{3}$ and RNAs (G4-RNAs) $)^{4}$ can affect the corresponding biological processes. G4-forming sequences are found within the genome and

17 transcriptome of several prokaryotes, eukaryotes and viruses ${ }^{5}$. Importantly, G4-forming sequences are

18 highly saturated at sites of disease-relevance such as oncogenes, telomere, and repeat expansion 19 regions $^{6}$. Biochemical ${ }^{7}$, bioinformatics ${ }^{8}$, optical imaging ${ }^{9}$ and genomic techniques ${ }^{7,10}$ have been used to

20 show that G4 formation is widespread in both the human genome and the transcriptome. However, 21 accurately quantifying and mapping by sequencing the G4-DNA $A^{11-14}$ and G4-RNA sites ${ }^{15,16}$ formed within

22 living cells continues to be an ongoing challenge. It is important to note that G4s formation is often 23 outcompeted by Watson-crick duplex formation, protein-binding, and G4-destabilizing helicase (G4- 
24 helicase $)^{17}$ activities; thus, the G4 folding process requires windows of opportunities when the

25 polynucleotides are single-stranded and in more openly accessible conformations. In support of this notion, it has been observed that open chromatin states are more favourable for the formation of G4-

$27 \mathrm{DNAs}^{13}$. The high prevalence of potential G4-forming sequences in the human genome ${ }^{8}$ suggests that

28 formation of G4s likely permeates throughout most, if not all, important biological events in the flow of 29 genetic information. G4-DNAs may play roles in various biological functions, including telomere maintenance, transcription regulation, epigenetic regulation, replication and recombination ${ }^{18}$. Despite

31 the increasing volume of research in the G4 field, much of the previous focus has been on G4-DNA

32 rather than G4-RNA. Given the established ability of RNA strands to fold into intricate structures, which

33 govern their functions ${ }^{19}$, and the superior thermostability of G4-RNA ${ }^{4}$, it is anticipated that G4-RNAs

34 constitute a significant proportion of all folded G4s within living cells. G4-RNA has also been implicated

35 in a wide range of biological processes, including translation, RNA processing, splicing, and ribonucleoprotein (RNP) formation ${ }^{4}$. Here, we discuss some of the current techniques used to study G4s and highlight our recently developed affinity-capture technique, called the G4-RNA-specific precipitation (G4RP) with sequencing (G4RP-seq), for studying G4-RNAs on a transcriptome-wide level.

41 While interest in G4s has been multiplying, there is still a limited number of techniques for studying G4s

42 on a genome- and transcriptome-wide scale. For genome-wide studies, G4-seq ${ }^{15}$ combines the

43 polymerase-stop assay with next-generation sequencing under conditions that favour (using K+ cations or G4-stabilizing ligand pyridostatin (PDS) ${ }^{20}$ ) or disfavour G4 formation (using Li+ cations) in purified, 45 protein-free DNA. As folded G4s can cause polymerase-stalling, quantification of these polymerization stop sites can infer G4 folding state and generate a genomic G4 map. While the resolution is high, a 
47 major limitation of G4-seq is the in vitro experimental setting, which is not representative of the native

48 chromatin state. Genome-wide G4 mapping by performing chromatin-immunoprecipitation sequencing

49 (G4-ChIP-seq) $)^{13}$ using the G4-specific antibody BG4 ${ }^{11}$, a single-chain variable fragment antibody specific

50 for G4, allows approximation of a more biologically relevant (i.e. "in vivo") setting. In comparison, G4-

51 seq observed over 750,000 potential G4 sites $^{12}$, whereas G4-ChIP-seq reported only 10,000 enriched

52 sites $^{13}$. This large discrepancy between the two techniques emphasizes the importance of the local

53 chromatin environment in the formation of G4-DNAs.

A recently developed sequencing technique, $\mathrm{rG} 4-\mathrm{seq}^{15}$, which is conceptually similar to G4-seq, has been implemented for studying transcriptome-wide G4-RNAs. This technique exploits the effect of G4-RNAs on the processivity of reverse-transcriptase (RT) in complementary DNA synthesis. By mapping

57 and comparing RT polymerization stop sites under G4-favourable and unfavourable ionic conditions in vitro, thousands of potential G4-RNA sites were discovered. As the query of G4 formation using purified RNA will not recapitulate the contributions of other biological factors (e.g. RNA-binding proteins, other nucleic acid structures.), rG4-seq possesses much of the same limitations as G4-seq. To that end, the RT stop-profiling method has been adapted to study G4-RNAs in vivo with an additional step of treating

62 cells with dimethyl sulfate (DMS) before purification and RT. DMS-modified guanine bases are unable to 63 fold into G4s in vitro and thus can be used to infer folding state in vivo indirectly ${ }^{21}$. Surprisingly, DMS/RTstop profiling showed that at equilibrium, G4-RNAs are nearly all unfolded in vivo, a significant departure from observations made using live-cell imaging ${ }^{9,22}$ and in vitro quantification ${ }^{15}$ methods. This apparent discrepancy is likely due to the nature of the DMS/RT-stop profiling assay, which may be more

67 suitable for establishing the shift of G4 equilibrium rather than capturing a snapshot of the folded G4 transcriptome. Drawing inspirations from G4-ChIP-seq, we developed the G4RP-seq protocol ${ }^{16}$, which 
71 these G4 folded states. Thus, the current model depicts G4-RNAs as short-lived structures which are

72 continuously being folded and unfolded by various regulatory mechanisms inside living human cells.

73 These findings present us with a new perspective in which G4-RNAs are portrayed more as events rather

74 than simple physical structures.

75

76

77

78

79

80

81

82

83

84

87

\section{Development of the Biotinylated Template-Assembled Synthetic G-quartet (BioTASQ) and G4RP}

\section{Protocol}

A common recurring challenge in designing $\mathrm{G} 4$ ligands has been the lack of specificity due to unintended off-target binding. A class of biomimetic probes, called the Template-Assembled Synthetic G-quartet $(\text { TASQ })^{23}$, was developed to mitigate these off-target binding events. The chemical design of TASQ, inspired by the natural formation of G-quartets in G4s, consists of a central core with four arms, each attached to a guanine (Fig. 1a). These guanines self-assemble into a synthetic G-quartet upon association with a G4 target through end-quartet stacking. The use of the synthetic G-quartet itself as the recognition molecule provides high specificity and defined binding properties. A caveat of TASQ is its preference for targeting G4s with a parallel conformation due to the accessible end-quartets for TASQ binding without steric hindrance from the loops. This binding preference is especially useful for targeting G4-RNAs due to their parallel-conformational constraints. The extra utility of TASQ molecules is demonstrated by swapping the central core with different application-specific moieties ${ }^{23-26}$. The newest generation of TASQ molecules is a biotinylated version of TASQ (BioTASQ) ${ }^{16,27}$, allowing for affinity capture of G4 targets using streptavidin-biotin interactions. G4RP is derived from a standard RNA immunoprecipitation (RIP) protocol ${ }^{28}$; however, instead of antibody-protein recognition in RIP, G4RP uses a ligand-nucleic acid structure recognition with BioTASQ. Like RIP and other similar methods, the G4RP protocol can be coupled with high-throughput sequencing to profile transcriptome-wide G4 distribution. 
95 Using G4 ligands as baits for G4 targets has previously been explored ${ }^{29}$; however, specificity for the

96 intended G4 targets has been an ongoing challenge for most, if not all, G4 ligands ${ }^{30}$. BioTASQ was

97 designed with these limitations in mind by providing higher specificity due to the strictly defined binding

98 mechanism. The use of a synthetic G-quartet as the bait provides the best-predicted interactions given

99 that G-quartet stacking interaction is obligatory and exclusive for all G4 formations and stabilization.

100 Some of the key advantages and limitations of G4-RNA quantification assays stem from whether the

101 approach is direct or indirect. Direct and indirect G4-RNA identification approaches provide different

102 perspectives due to the dynamics of G4-RNA formation, and thus the appropriate method of choice

103 depends on the specific scientific question. Table 1 outlines some of the key differences between the

104 two types of methods. We consider G4RP a direct approach to detect G4s due to the probe's direct

105 association with the G4 target. However, direct approaches do have the potential pitfall of probe-

106 assisted stabilization of the G4 targets. Since BioTASQ has properties of a G4 ligand, it conceivably can

107 stabilize G4 targets, resulting in quantification biases in capturing G4-RNAs that are not representative

108 of their true biological states. Therefore, an in vivo crosslinking step is added prior to cell lysis and

109 BioTASQ-assisted pulldown in G4RP, which is crucial in minimizing this bias by preventing G4-folding in

110 vitro. In contrast, indirect approaches, including rG4-seq ${ }^{15}$ and DMS/RT-stop profiling ${ }^{21}$, involve nucleic

111 acid modifications prior to subsequent screening using reverse transcriptase. Indirect approaches

112 heavily rely on the following two assumptions: first, modifying chemicals are assumed to access all

113 cellular RNA and modify unprotected sites uniformly within the transcriptome of living cells, which is

114 unlikely; second, in vitro folded G4s are presumed to be the sole cause of all RT stop sites, which may

115 lead to overestimation of the actual number of G4 sites due to the inclusion of potential polymerase-

116 stalling effects by other RNA structures ${ }^{19}$. Indirect approaches are likely biased against highly dynamic

117 RNA structures as these readouts can only be estimated from highly stable structured RNAs under the 
118 set of experimental conditions ${ }^{31}$. Depending on the experimental conditions, when the labelling

119 chemicals are usually not the limiting reagent, chemical modification in live cells can often lead to

120 overwhelmingly modified RNAs. Thus, G4RP is considered a more appropriate method for providing a

121 less-biased view of transiently formed G4 structures. Finally, the currently reported indirect methods do

122 not consider the formation of intermolecular G4-RNA since the principle of RT-stop profiling is based on

123 the effect of the cis-acting intramolecular G4s. In this sense, G4RP provides measurements that are

124 more representative of the biologically relevant interactions due to its ability to reporting on both intra-

125 and inter-molecular folded G4-RNAs.

126 As indirect methods often provide high resolution data at near single base levels (e.g. chemical probing

127 techniques, RT-stop profiling), a major limitation of G4RP is the lack of mapping resolution (>200 bases)

128 due to the sonication step. The main challenge lies in striking a balance between over-sonication and

129 under-sonication. Under-sonication prevents the proper release of cellular content, resulting in a

130 reduction in resolution and lower pulldown efficiency. In contrast, over-sonication may increase

131 mapping resolution but may also lead to disruption of the binding structure (G4 end stack) necessary for

132 BioTASQ binding. Optimization to reach the specific goals of the experiment is highly recommended.

133 While sequence analysis of the BioTASQ-enriched RNA fraction in G4RP shows robust enrichment of G-

134 rich sequences, it should be noted that a minor portion of indirect interactions could be crosslinked and

135 captured.

136 While G4RP does offer several advantages over the indirect polymerase-dependent methods, the choice

137 of G4-RNA quantification method depends on the biological questions of interest. It is important to

138 emphasize that no individual method is without limitations and caveats, and that necessary future steps

139 should be invested in combining complementary methods in order to mitigate some of their individual

140 limitations, thus providing a more unbiased view of the G4-RNA transcriptome. 
Table 1. Indirect vs direct methods in studying transcriptomic G4-RNAs

\begin{tabular}{|c|c|c|}
\hline & $\begin{array}{l}\text { Indirect method } \\
\text { (rG4-seq, DMS/RT-profiling) }\end{array}$ & $\begin{array}{l}\text { Direct method } \\
\text { (G4RP-seq) }\end{array}$ \\
\hline Readout method & $\begin{array}{l}\text { Reverse-transcription stalling + } \\
\text { sequencing }\end{array}$ & $\begin{array}{l}\text { Probe-binding/extraction + } \\
\text { sequencing }\end{array}$ \\
\hline $\begin{array}{l}\text { Methods to capture } \\
\text { biological state }\end{array}$ & $\begin{array}{l}\text { Modification of nucleic acids in live } \\
\text { cells }\end{array}$ & Chemical crosslinking \\
\hline Resolution & High & Low \\
\hline Targets & -Intramolecular G4s & $\begin{array}{l}\text {-Intramolecular G4s } \\
\text {-Intermolecular G4s }\end{array}$ \\
\hline Enrichment method & Poly $(A)$ enrichment & Ribo-depletion \\
\hline Biases/ Limitations & $\begin{array}{l}\text {-in vitro biases } \\
\text {-DMS modification could lead to } \\
\text { underestimation of dynamic } \\
\text { structures } \\
\text {-Overestimation of G4 structures } \\
\text { by counting stops induced by other } \\
\text { structures } \\
\text {-Not able to read 5' G4 if there is a } \\
\text { strong RT stop caused by 3' G4 } \\
\text { signal }\end{array}$ & $\begin{array}{l}\text {-Probe-assisted stabilization could } \\
\text { lead to overestimation of G4 } \\
\text { structures } \\
\text {-a small portion of crosslinked indirect } \\
\text { interactions could be captured }\end{array}$ \\
\hline
\end{tabular}

143 Theoretically, G4RP could be combined with chemical modification and in vitro RT-stop profiling to 144 generate a high-resolution map of transcriptome-wide G4-RNA sites; however, sample processing compatibilities and assay optimization between these methods have not yet been tested. RT-stop

146 profiling could be performed in parallel with G4RP on the same set of samples and subsequently

147 analyzed and compared. Alternatively, RT-stop and G4RP could be performed sequentially by profiling

148 BioTASQ-captured RNA to improve resolution. It is also yet to be determined how chemical modification

149 (e.g. through DMS), if incorporated, could affect G4RP. While G4RP-seq could be used to infer in vivo

150 folded state, rG4-seq (or equivalent RT-profiling methods) could be used to determine at high resolution 
151 the positions in which intramolecular G4s are more likely to form in vitro. Further optimization of the

152 sonication step (i.e. increasing sonication duration) and/or adding ribonucleases could potentially

153 improve resolutions of G4RP-seq by decreasing fragment sizes. However, these optimization strategies

154 are limited to improving the resolution of intramolecular G4s. Intermolecular G4s remain a challenge to

155 map with the currently known techniques. The use of different crosslinking agents (e.g. psoralen) with

156 different effective distances could also be informative to elucidating a complete picture of the G4-RNA

157 interactions. Integration of G4RP-seq with other methods for identifying RNA-RNA interactions, such as

158 LIGR-seq ${ }^{32}, \mathrm{MARIO}^{33}, \mathrm{SPLASH}^{34}$, and PARIS ${ }^{35}$, may aid in identifying long-range interactions through G4s.

159 G4RP may also be potentially useful, when coupled with proteomics, in identifying protein partners that

160 may interact with G4-RNAs. While the G4RP protocol has initially been optimized for human cells, it can

161 conceivably be adapted and optimized for other model organisms, including other eukaryotes,

162 prokaryotes and even viruses ${ }^{5,36}$. Given the unique G4 profiles of different organisms and species, G4RP-

163 seq may be valuable for studying the evolution of G4-interactome and potential inter-organism

164 interactions (e.g. host-pathogen) ${ }^{37}$.

\section{Experimental Design}

166 Selection of cell models and treatment endpoints. G4RP is expected to be compatible with most

167 mammalian cell lines. The samples should be chosen with appropriate controls to ensure an unbiased

168 comparison (e.g. vector controls for overexpression experiments). Comparisons between cell lines

169 should include ones with similar genomic backgrounds. Typically, for drug treatments (e.g. small-

170 molecule compounds such as G4 ligands: BRACO-19 and RHPS4 ${ }^{16,27}$ ), a dose-response profile for an

171 observable endpoint should be generated to assess the appropriate doses for subsequent experiments.

172 This would ensure that the intracellular concentration of the ligand is sufficient to cause a biologically

173 observable change in an endpoint (e.g. cytotoxicity) without leading to excessive cell death and 
174 subsequently the loss of sample. We suggest using subtoxic or low toxic dose (LD5-25; dose producing 5-

$17525 \%$ of cell deaths). For classical G4 ligands, such as BRACO-19 and RHPS4, we have observed optimal 176 concentrations ranging from 0.5 to $20 \mu \mathrm{M}$ depending on the cell line. For treatments, the vehicle (i.e.

177 solvent for compound) should be used as the control. Another factor of consideration is the duration of

178 the treatment. Typical treatment time points include $6 \mathrm{~h}, 12 \mathrm{~h}, 24 \mathrm{~h}, 48 \mathrm{~h}$ and $72 \mathrm{~h}$. A different endpoint 179 measure, other than cytotoxicity, may be chosen depending on the experimental goals.

Chemical crosslinking. Crosslinking could also impact sonication efficiency; however, we advise against

181 deviating from our recommended crosslinking duration of 5 to $10 \mathrm{~min}$. Most formaldehyde

182 formulations, including those with methanol additive, are effective for crosslinking. Methanol increases

183 cell permeabilization, which may increase crosslinking efficiency. Since formaldehyde is sensitive to light

184 and air, we suggest storing it in aliquots in a dark and sealed environment. Fresh formaldehyde without

185 methanol, sold in ampules, can also be considered to decrease potential variability.

186

187

Sonication and fragmentation. Fragmentation of the RNA material is required for the G4RP. Typically, the range of fragments should fall between $200-800 \mathrm{nt}$ with centering around $400-500 \mathrm{nt}$. Gel electrophoresis coupled with RNA-staining dye is a simple method for test. Other techniques requiring more advanced equipment, such as a Bioanalyzer, can also be used. We suggest using mechanical sonication as it is more consistent and sonication devices are commonly available in most institutions. However, different sonicators (e.g. Covaris ultrasonicator, Diagenode Bioruptor, Branson Sonifier, or other equivalent equipment) will require additional optimization. We recommend testing a range of sonication durations, with the optimal total sonication duration likely to be between 2 to 4 minutes. Different sonicators may have a recommended range in terms of the input number of cells. Please check with the manufacturer-supplied manual or recommended protocols as a guide for the initial optimization. Sonicators used for G4RP should also be equipped with a temperature control system to 
prevent heating and premature crosslink reversal. Mechanical sonication serves two purposes: lysing the

198 cell and fragmenting the nucleic acids. Use of any other non-mechanical shearing alternatives (e.g. detergent-based lysis and nuclease-mediated fragmentation) will require a different set of optimization and additional considerations of potential biases.

201 Bead binding. Our protocol is optimized using magnetic streptavidin-coupled beads, specifically the 202 Promega Streptavidin MagneSphere. Other brands or types of streptavidin-coupled beads (agarose) are 203 likely to be compatible with BioTASQ as well; however, additional optimization and validation may be necessary. BioTASQ concentration should greatly exceed the binding capacity to ensure the capture is 205 driven by BioTASQ, not by non-specific binding to the beads. Typically, each G4RP capture uses 10-20 nmol of BioTASQ with 50-100 $\mu$ g of beads. Increasing the amount of beads or switching to high-capacity 207 beads can increase the capture yield. When altering the amounts of beads used, negative controls must 208 be tested in parallel.

209 Negative control and normalization. There are two types of controls used in G4RP. For the negative control, G4RP is performed in the same manner with biotin instead of BioTASQ. The yield of purified

211 RNA from the negative G4RP control sample is typically much lower and serves as a control for non212 specific bindings to the beads. The negative control is necessary for early optimization but is optional 213 after the protocol has been optimized and only negligible background is detected. The input control, a 214 small aliquot of the material collected prior to BioTASQ binding, is critical and required for all 215 experiments. In contrast with genomic DNA, cellular RNA content can vary widely, and this input control 216 serves as an internal control for each G4RP experiment during the normalization step of the analyses.

217 PCR Primer selection. We have included a list of recommended targets for checking the efficiency of 218 G4RP (Table 2). However, if there are other targets of interest, additional sets of primers may be used. 219 These primers should undergo standard validation for specificity to the target region and PCR efficiency. 
Typically, at least three biological replicates should be used to quantify each locus. For sequencing, we

221 recommend having multiple replicates (at least 4-6). Based on the results of qPCR screening, the best 2-

2223 replicates can be used for library preparation. Any newly discovered region of interest from

223 sequencing analyses should also be validated using qPCR and appropriate primers.

224 Library preparation and sequencing depth. For library preparation of the G4RP samples, we highly

225 recommend the use of ribodepletion over poly-A enrichment. Due to the fragmentation step in G4RP-

226 seq, poly-A selection will likely result in loss of signal and a significant 3' bias. Always use the minimal

227 number of PCR cycles for the library generation. In the case of low amount of input, consider pooling

228 multiple parallel-processed samples to increase concentration. Sequencing depth will depend on the

229 experimental question. We recommend 15-20 million uniquely mapped reads; however, this could be

230 scaled up to 50 million reads to detect rarer events or changes. Typically, sequencing 2-3 replicates for

231 each BioTASQ-enriched sample is sufficient for cost-effective data analysis. More replicates would

232 improve the robustness of the statistical analysis but are unlikely to change the overall conclusions of

233 the experiment. Sequencing of the negative control is optional and is unlikely to result in any useful data

234 due to the low levels of the transcriptome of interest and significant rRNA background. Each condition

235 must be accompanied by the sequencing of at least one input control. Ideally, for the most robust

236 normalization, each BioTASQ-enriched sample can be accompanied by its respective input control.

\section{MATERIALS}

\section{Biological materials}

240 Cell lines of interest. We have used G4RP successfully in variety of transformed or cancer-derived human

241 cell lines of different types, including MCF7 (https://scicrunch.org/resolver/CVCL_0031), MDA MB-231 
242 (https://scicrunch.org/resolver/CVCL_0062), HELA (https://scicrunch.org/resolver/CVCL_0030), HEK293

243 (https://scicrunch.org/resolver/CVCL_0045), and HT29 (https://scicrunch.org/resolver/CVCL_0320).

244 With proper optimization of later steps, we expect G4RP to be compatible with most organisms. Here,

245 our protocol focuses on cultured cell lines. The use of tissue may also be compatible but will require

246 additional optimization of tissue homogenization, crosslinking and sonication steps.

247 CAUTION: The cell lines used in your research should be regularly checked to ensure they are authentic

248 and are not infected with mycoplasma.

249 Reagents

250 CRITICAL Most standard molecular and cell biology grade reagents can be obtained from various

251 vendors and do not need to be from the ones specified here.

252 Cell culturing

253 - Dulbecco's Modified Eagle Medium (DMEM) (Gibco, cat. no. LS11965092)

254 - Fetal bovine serum (FBS) (GE Lifescience, cat. no. SH3039602)

255 - Penicillin-streptomycin (P/S) (Gibco, cat. no. 151140148)

256

257 Standard buffer components in the G4RP protocol

258 - Nuclease-free water (Thermos, cat. no. AM9922 or vendors of choice or made in-house using

$259 \quad$ DEPC treatment)

260 - Diethyl pyrocarbonate (DEPC) (Sigma, cat. no. D5758)

261 - Formaldehyde (37\% wt/vol) (Sigma, cat. no. 252549)

262 CRITICAL: Keep away from light and air; aliquot before use.

CAUTION: Formaldehyde is toxic through ingestion, inhalation and skin contact. Always wear appropriate personal protective equipment and operate only inside a fume hood. All waste material should be collected separately and disposed according to institutional procedures. 
- Glycine (Fisher, cat. no. G45-212)

- $\quad$ 10X PBS (Fisher, cat no. BP39920)

- HEPES (Sigma, cat. no. H3375)

- $\mathrm{NaCl}$ (Fisher, cat. no. S271-10)

- EDTA (Sigma, cat. no. E5134)

- EGTA (Sigma, cat. no. E3889)

272

- $\mathrm{KCl}$ (Fisher, cat. no. P330)

273

- DTT (Fisher, cat. no. R0861)

- IPEGAL (NP40) (Sigma, cat. no. 13021)

275

- $\quad$ Tris (Fisher, cat. no. BP152)

- Chloroform (Sigma, cat. no. C2432)

278

- Isopropyl alcohol (Sigma, cat. no. 19516)

281

- Ethyl alcohol

- RiboLock RNA inhibitor (ThermoFisher, cat. no. EO0381)

- Protease-inhibitor cocktail (PIC) (optional; usually supplied as 100X; NEB \#5871S)

- TRIZOL (Invitrogen, cat. no. 15596026) 
- Biotin (Sigma, cat. no. 2031)

291

- BioTASQ (available soon through Merck/MilliporeSigma)

- Promega Magnesphere Paramagnetic (Streptavidin beads) (Promega, cat. no. Z5481)

293

294

295

296

297

298

299

300

301

302

$\underline{\text { Reverse Transcription and PCR }}$

- Superscript III (Invitrogen, cat. no. 18080093)

- Random hexamer pd(N)6 (Invitrogen, cat no. N8080127)

- $\quad$ dNTP mix (NEB, cat no. N0447L)

- $\quad$ SYBR green PCR-mix (BioRad, cat. no. 1725120)

\section{Agarose Gel reagents}

- UltraPure Agarose (ThermoFisher, cat. no. 16500100)

- Bleach (Clorox)

- $\quad$ SYBR Green II RNA Gel Stain (ThermoFisher, S7564)

\section{Sequencing kits}

- RNEasy Plus RNA purification kit (Qiagen, cat. no. \#74134)

CRITICAL: Illumina Ribo-Zero has been discontinued and incorporated into the TruSeq Stranded Total RNA kit. Use either the old Illumina Ribo-Zero + TruSeq RNA library kit or the new Illumina Stranded Total RNA library prep kit.

- Old version: Illumina Ribo-Zero + TruSeq RNA library prep kit (Illumina, cat. no. RS-122-2001)

- New version: TruSeq Stranded Total RNA library prep (Illumina, cat. no. 20020596)

\section{Equipment}

\section{$\underline{\text { Lab equipment }}$}

- Standard cell culture incubator (e.g. HERACell, Thermos)

- Standard Benchtop centrifuge (e.g. Eppendorf)

- Temperature controlled centrifuge (or a standard unit in a refrigerated environment)

- Standard laboratory rocker 
- Standard benchtop aspirator

- Cell sonicator (e.g. Covaris Ultrasonicator, Diagenode Bioruptor, Branson Sonifier)

- Tube rotator

- Nanodrop spectrophotometer (Thermos)

- Thermal cycler (Bio-Rad)

- Real-time PCR detection system (Bio-Rad)

322

- Gel imager (Alpha Innotech)

323

- Illumina HiSeq, NextSeq or NovaSeq sequencer

324 Other consumables

325

- Cell and tissue culture dishes (vendor of choice)

- Cell culture treated flasks (vendor of choice)

- Cell scrapers (Corning, cat. no. 3011)

- Wide-mouth tips (VWR, cat. no. 89049)

- Covaris microtube AFA Fiber Pre-Slit Snap-Cap (Covaris, cat. no. 520045)

- $\quad$ PCR 8-tube strip and caps (Bio-Rad, TLS0851)

- Hard-shell 96-well PCR plate (Bio-Rad, HSP9601)

Bioinformatics Tools

- Trimmomatic $^{38}$ - https://github.com/timflutre/trimmomatic

- $\quad$ HISAT2 ${ }^{39}$ (https://scicrunch.org/resolver/SCR_015530) - http://daehwankimlab.github.io/hisat2/

- Integrative Genomics Viewer ${ }^{40}$ (https://scicrunch.org/resolver/SCR_011793) http://software.broadinstitute.org/software/igv/

- HTSeq-count ${ }^{41}$ (https://scicrunch.org/resolver/SCR_005514) https://htseq.readthedocs.io/en/master/ 
- DESeq $2^{42}$ (https://scicrunch.org/resolver/SCR_015687) https://doi.org/doi:10.18129/B9.bioc.DESeq2

CRITICAL: All buffers should be sterile and carefully prepared using RNase-free water.

$0.1 \% \mathrm{vol} / \mathrm{vol}$ DEPC-treated water can be made by adding $1 \mathrm{~mL} \mathrm{DEPC}$ to $1000 \mathrm{~mL}$ of $\mathrm{ddH}_{2} \mathrm{O}$. Mix and incubate at room temperature $\left(20-22^{\circ} \mathrm{C}\right)$ for $1 \mathrm{~h}$ before autoclaving.

\section{DEPC-PBS}

Dilute 10X PBS (RNase-free) to $1 \mathrm{X}$ in DEPC $\mathrm{H}_{2} \mathrm{O}$ or nuclease-free water from a vendor. Store at room temperature.

1X Fixing buffer (50 mM HEPES KOH pH 7.5, 100 mM NaCl, 1 mM EDTA pH 8.0, 0.5 mM EGTA pH 8.0 in DEPC $\mathrm{H}_{2} \mathrm{O}$ )

Prepare a $5 \mathrm{X}$ stock solution and store at room temperature for at least 1 year.

\section{M Glycine}

Prepare in DEPC $\mathrm{H}_{2} \mathrm{O}$ and filter sterilize. Store at $4^{\circ} \mathrm{C}$ for up to 2 months.

G4RP Buffer (150 mM KCl, 25 mM Tris pH 7.4, 5 mM EDTA, 0.5 mM DTT, 0.5\% vol/vol NP40 in DEPC $\mathrm{H}_{2} \mathrm{O}$ or nuclease-free water)

Prepare the stock buffer and store at $4^{\circ} \mathrm{C}$ for at least 1 year. A working stock should be made for every new experiment by transferring the required amount for the experiment to a conical tube and adding fresh RNase inhibitor. Use the manufacturer-recommended amount of RNAase (typically $\sim 100 \mathrm{U} / \mathrm{mL}$ of buffer). Optionally, fresh 1 X PIC may be added, especially if the downstream application involves protein.

\section{$1 \mathrm{mM}$ Biotin}

Make $1 \mathrm{mM}$ stock using pure $\mathrm{ddH}_{2} \mathrm{O}$. Can be stored at $4^{\circ} \mathrm{C}$ for at least 3 months. 
Make $1 \mathrm{mM}$ stock using pure $\mathrm{ddH}_{2} \mathrm{O}$. Can be stored at $4^{\circ} \mathrm{C}$ for at least 6 months.

Always mix well before transferring beads with a pipette using wide-mouth pipette tips. The magnetic beads are stored in a stabilizing buffer (with PBS/ $0.02 \% \mathrm{wt} / \mathrm{vol}$ sodium azide/ $1 \mathrm{mg} / \mathrm{mL}$ BSA). You may gently mix well with tapping and aliquot to small volumes (e.g. $30 \mu \mathrm{L}$ ) for later use. For a new experiment, prepare the beads by washing in $1 \mathrm{~mL}$ of DEPC-PBS 3 times with Make 50X stock and store at room temperature.

\section{PROCEDURE}

CRITICAL The G4RP protocol itself can be completed in two days. Prior to G4RP, cell culture and live-cell

379 chemical treatment steps can take a few days to a week to set up. It is recommended that the weekly

380 schedule is planned to avoid any interruption in the experimental pipeline. In case there are time

381 constraints or other factors that cause anticipated interruptions, we have included a recommended

382 pause point in which the experiments can be temporarily halted and resumed later. Please refer to Fig.

$3831 \mathrm{~b}$ for an overview of the protocol.

\section{Seeding cells and treatment with G4 ligands TIMING: 2 days to 1 week}

1) Seed and treat cells as necessary in DMEM culture medium supplemented with FBS and P/S (or with 
Generally, for most cell lines, 250,000-1,000,000 cells (minimum 150,000 cells) are seeded per $10 \mathrm{~cm}$ dish for a 3-4 days experiment (including seeding, cell growth and 2-3 day treatments). Seeding density can be scaled for a shorter or longer experimental period. The exact timeframes need to be optimized for different cells and treatments. Typically, the cells are harvested while in the log-phase growth with confluence at around 60-90\%.

CRITICAL STEP: If G4 ligand treatment is used, make sure a suitable dose is chosen. Cell lines can respond differently to different G4 ligands. A dose-finding experiment should be performed, and a low-toxic (LD15 to LD25) dose should be chosen for subsequent experiments.

\section{Crosslinking TIMING: 1-2 h}

CAUTION: Formaldehyde is highly toxic. Always handle high concentrations ( $>4 \%$ formaldehyde) of 397 formaldehyde inside the chemical fume hood. Diluted (1-4\%) formaldehyde may be used outside of 398 hood briefly (<10 min). After the crosslinking step, all formaldehyde waste should be placed in a 399 separate waste container in the fume hood to be disposed of appropriately according to institutional 400 procedures.

401 2) Make fresh $1 \% \mathrm{vol} / \mathrm{vol}$ formaldehyde in $1 \mathrm{X}$ Fixing Buffer before a new experiment.

402 3) Aspirate media and wash once with $10 \mathrm{~mL}$ of DEPC-PBS

403 4) Aspirate PBS and add $10 \mathrm{~mL}$ of $1 \%$ formaldehyde/ $1 X$ Fixing Buffer to a $10 \mathrm{~cm}$ dish for $5 \mathrm{~min}$ on a 404 rocker at room temperature.

405 5) Quench crosslinking by adding glycine to a final concentration of $125 \mathrm{mM}$ and incubate $5 \mathrm{~min}$ on a 406 rocker at room temp. CRITICAL STEP: The duration of the formaldehyde crosslinking step is important. Try to keep it as consistent as possible between samples. Stagger the addition of formaldehyde and quenching if processing several samples at the same time. You may want to optimize the duration of crosslinking. 
It should generally be between 5 to 10 minutes. Typically, crosslinking over 10 minutes is not

411 recommended as over-crosslinking may limit the accessibility of epitopes.

412 CRITICAL STEP: After the crosslinking step, keep the sample at $4^{\circ} \mathrm{C}$ as much as possible.

413 Centrifugation should be done at $4^{\circ} \mathrm{C}$ as well. All buffers from this point on need to be RNase-free.

414 6) Remove the fixing solution, add $0.8 \mathrm{~mL}$ of DEPC-PBS (pre-chilled) and scrape cells into an Eppendorf $415 \quad$ tube. Keep on ice.

416 7) Spin tubes at $1500 \mathrm{rpm}(200 \times \mathrm{g})$ for $3 \mathrm{~min}$ at $4^{\circ} \mathrm{C}$.

417 8) Aspirate supernatant (avoid disturbing the cell pellet) and wash again with $1 \mathrm{~mL}$ of DEPC-PBS.

$418 \quad$ Aspirate the supernatant and discard.

419 PAUSE POINT: You may freeze down the cell pellets at this stage and store them at $-20^{\circ} \mathrm{C}$ to be 420 processed later. The pellets can be stored for at least 2 months. However, for optimal results, we 421 recommend that you do not pause at this point as processing fresh samples generally gives a better and 422 more consistent yield for the final RNA targets from G4RP.

\section{Sonication (TIMING: 1-2.5 h)}

424 9) Resuspend the pellet in $400 \mu \mathrm{L}$ G $4 R P$ buffer (supplemented with $100 \mathrm{U} / \mathrm{mL}$ RNase inhibitor; it is 425 optional to add 1XPIC). If cell pellets were frozen, thaw on ice for 30 min before resuspending in 426 G4RP buffer. ? TROUBLESHOOTING

10) Sonicate on a Covaris m 220 focused ultrasonicator using $10 \%$ duty factor "Chromatin Shearing" 429 preset for 2 min at $7^{\circ} \mathrm{C}$ temperature setpoint. The Covaris AFA Fiber microtube- 130 is used for the sonication. Mix well before adding the resuspended cells to the tube. Make sure there are no 431 bubbles when adding the sample to the AFA microtubes prior to sonication. Each sonication tube 
should contain exactly $130 \mu \mathrm{L}$ corresponding to approximately $2-3$ million cells. Repeat until all the

433 resuspended cells are sonicated.

CRITICAL STEP: Optimization with specific sonicators (Covaris, Diagenode, and other brands) is required. The sonication protocol should be similar to that recommended for ChIP according to sonicator-specific published protocols. We recommend that different durations of sonication be tested. Generally, the sonication duration should not exceed that recommended for ChIP, and a good starting point for optimizing the duration is to use half of what is recommended for ChIP. Make sure the temperature is kept around $2-7^{\circ} \mathrm{C}$. Sonication can be checked by proceeding to Steps $22-36$ and running a $1 \%$ bleach gel $^{43}$ as outlined in Mini-procedure Box (Fig. 2a).

Mini-procedure Box: RNA bleach gel

1. Make a gel mix with a final concentration of $1 X$ TAE buffer and 1.5\% Agarose in ddH2O.

2. Microwave until boiling then swirl to mix

3. Add bleach to final concentration of $1 \%$, microwave to boil again. Swirl to mix.

445 4. Pour gel mix into gel cast. Let gel cool.

$446 \quad$ 5. Load RNA samples with $1 X$ loading dye. Run at $100 \mathrm{~V}$ for $45 \mathrm{~min}$.

6. Post-stain using SYBR Green dye diluted 1:5000 in 1X TAE buffer for 30 min away from light.

11) Spin sonicated lysate at $13200 \mathrm{rpm}(16100 \mathrm{xg})$ for $10 \mathrm{~min}$ at $4^{\circ} \mathrm{C}$. Move the supernatant to new tubes. The supernatant (sonicate), containing the cellular materials that are successfully released from sheared cells, will be used for the subsequent steps. 
PAUSE POINT: It is possible to freeze down the sonicate for later processing. Consider using this

454 pause point rather than the previous one if the issue with the clumpy frozen cell pellets arises. However, for optimal results, it is recommended to continue directly to the next step.

\section{Binding and washes TIMING: $\mathrm{O} / \mathrm{N}+4 \mathrm{~h}$}

457
12) Each sonicate of $\sim 390 \mu \mathrm{L}$ can be aliquoted into two tubes (each with $180 \mu \mathrm{L}$ ): one for the biotin control and the other for BioTASQ. If the volume is insufficient $(<360 \mu \mathrm{L})$, the volume can be adjusted by adding the small amount of the remaining G4RP buffer, prepared previously, to a final volume of $390 \mu \mathrm{L}$. Save $8.75 \mu \mathrm{L}$ of the remaining sonicate as a $5 \%$ input control. The input control can be stored temporarily at $4^{\circ} \mathrm{C}$ then processed later with the other samples.

13) Add $20 \mu \mathrm{L}$ of $1 \mathrm{mM}$ stock biotin $(20 \mathrm{nmol})$ to a final concentration of $100 \mu \mathrm{M}$ to the control tube. Add $20 \mu \mathrm{L}$ of $1 \mathrm{mM}$ stock BioTASQ $(20 \mathrm{nmol})$ to a final concentration of $100 \mu \mathrm{M}$ to the G4RP tube.

14) Incubate overnight at $4^{\circ} \mathrm{C}$ on a rotator.

15) Next day, use wide-mouth tips to add $10 \mu \mathrm{L}$ of MagneSphere magnetics beads (60 $\mu \mathrm{g}$ ) to each tube. CRITICAL STEP: The amount of magnetic bead added can be optimized. The recommended amount is between $20-100 \mu \mathrm{g}$, depending on the brand and make of the magnetic beads. An optimization experiment using different amounts of beads is highly recommended. Generally, a higher amount increases yield but also increases non-specific background binding. Always mix well before transferring the beads to another tube.

16) Incubate for $2 \mathrm{~h}$ at $4^{\circ} \mathrm{C}$ on a rotator.

17) Use the magnet to pull beads to the side by leaving tubes on the magnet for $2 \mathrm{~min}$. Shift the tubes slightly to pull beads closer together. Aspirate carefully without removing the beads.

18) Wash beads 3 times using $1 \mathrm{~mL}$ of G4RP buffer. Put on rotator at room temp for $5 \mathrm{~min}$ for each wash.

19) Wash 2 times in $1 \mathrm{~mL}$ of DEPC-PBS for 2 min each. 
477 20) Resuspend beads in $100 \mu \mathrm{L}$ of DEPC-PBS (supplemented with RNAse inhibitor). Take out the $5 \%$

478 input saved from Step 12 and add $100 \mu$ LEPC-PBS (with RNase inhibitor) to it as well.

$47921)$ Incubate at $70^{\circ} \mathrm{C}$ for $1 \mathrm{~h}$ to reverse crosslinks.

480 RNA purification TIMING: $\mathbf{2} \mathbf{h}$

481 CAUTION: TRIZOL and chloroform should be handled in the chemical fume hood. Waste should be 482 disposed of appropriately according to institutional procedures.

483 22) Add $1 \mathrm{~mL}$ of TRIZOL to each tube directly to the beads and mix gently by flicking the tubes $10-15$

484 times.

485 23) Incubate the sample in TRIZOL for 5-10 $\mathrm{min}$ at room temp to dissociate any ribonucleoproteins

$486 \quad$ (RNPs) and other structures.

487 24) Add $0.2 \mathrm{~mL}$ of chloroform. Make sure the cap is sealed and vigorously shake for $15 \mathrm{~s}$. Leave at room $488 \quad$ temp for $3 \mathrm{~min}$.

489

25) Centrifuge at $12000 \times \mathrm{g}$ for $15 \mathrm{~min}$ at $4^{\circ} \mathrm{C}$. The mixture will separate into the top aqueous phase, the middle interphase and the lower pink-coloured organic phase. The aqueous phase contains the RNA.

491 26) Transfer the aqueous phase to a new tube by tilting the tube at $45^{\circ}$ and slow pipetting. Avoid 492 disrupting the interphase/organic phase.

493

27) Add $0.5 \mathrm{~mL}$ of fresh isopropanol to the tube with the aqueous phase. Incubate at room temp for 10

$494 \min$.

495 28) Centrifuge for $10 \mathrm{~min}$ at $12000 \times \mathrm{g}$ at $4^{\circ} \mathrm{C}$.

CRITICAL STEP: The RNA pellet will be very small and unlikely to be seen by naked eye. Do not touch the bottom of the tube with the pipette. Pipette out slowly by drawing against the side of the tube.

49930 ) Add $1 \mathrm{~mL}$ of fresh $75 \%$ (vol/vol) ethanol. 
PAUSE POINT: You may store pellets in ethanol at $4^{\circ} \mathrm{C}$ for up to 3 days or $-20^{\circ} \mathrm{C}$ for months.

$50131)$ Vortex briefly and centrifuge at $7500 \times \mathrm{g}$ for $5 \mathrm{~min}$ at $4^{\circ} \mathrm{C}$.

502 CRITICAL STEP: It is unlikely that you will see a pellet here, as the amount of RNA is very low. Avoid 503 touching the pipette tip to the bottom or creating any motion that could disturb the pellet. The addition of $25 \mu \mathrm{g}$ of linear acrylamide during isopropanol precipitation step may also be considered 505 to assist with recovery and visualization.

506 32) Slowly remove the ethanol leaving approximately $10 \mu \mathrm{L}$ of liquid at the bottom of the tube.

507 33) Keep the lids of the tubes open and air dry for 10 min at room temp.

508 34) Add $30 \mu \mathrm{L}$ of RNAse-free water and pipette up and down.

$50935)$ Incubate at $55^{\circ} \mathrm{C}$ for $15 \mathrm{~min}$.

$51036)$ Check RNA concentration and quality using Nanodrop. ? TROUBLESHOOTING PAUSE POINT: RNA samples can be stored long term at $-70^{\circ} \mathrm{C}$. Freezing and thawing should be 513 minimized to avoid RNA degradation. We recommend to immediately process the reverse transcription-qPCR to check for G4RP efficiency. The remaining stored samples may be used to

\section{Reverse transcription and qPCR quantification TIMING: 4-5 $\mathrm{h}$} quick pulse with a centrifuge. Do not vortex.

37) Thaw purified RNA (including all G4RP, biotin control, and input control samples) from Step 36 on ice.

521 38) A master mix can be made with pdN6 and dNTP. Add $2 \mu \mathrm{L}$ to each tube containing RNA and mix: 


\begin{tabular}{lll}
\hline Component $\left(\mathbf{1}^{\text {st }}\right.$ part) & Amount $(\boldsymbol{\mu L})$ & Final concentration in RT reaction \\
\hline Purified RNA sample from Step 36 & 12.5 & varies \\
$50 \mu \mathrm{M}$ random hexamer (pdN6) & 1 & $2.5 \mu \mathrm{M}$ \\
$10 \mathrm{mM}$ dNTP mix & 1 & $500 \mu \mathrm{M}$ \\
\hline
\end{tabular}

522

$523 \quad 39)$ Incubate at $65^{\circ} \mathrm{C}$ for $5 \mathrm{~min}$.

524 40) Place on ice for $5 \mathrm{~min}$.

525 41) Make a master mix of the following components and gently mix by flicking. Add $20 \mu \mathrm{L}$ to each tube:

\begin{tabular}{lll}
\hline Component $\left(2^{\text {nd }}\right.$ part $)$ & Amount $(\mu \mathrm{L})$ & Final concentration in RT reaction \\
\hline 5X first strand buffer & 4 & $1 \mathrm{X}$ \\
0.1 M DTT & 1 & $5 \mathrm{mM}$ \\
RNAse inhibitor $(40 \mathrm{U} / \mu \mathrm{L})$ & 0.25 & $10 \mathrm{U}$ \\
Superscript III $(200 \mathrm{U} / \mu \mathrm{L})$ & 0.25 & $50 \mathrm{U}$ \\
\hline Total & 20 & \\
\hline
\end{tabular}

526

527 42) Gently mix by flicking the RT reaction tube and pulse spin by brief centrifugation.

528 43) Incubate at room temp for $5 \mathrm{~min}$.

529 44) Then, incubate at $55^{\circ} \mathrm{C}$ for $45 \mathrm{~min}$. These incubations (steps $43-45$ ) can be performed on a

530 thermocycler.

531

45) Inactivate reaction by incubating at $70^{\circ} \mathrm{C}$ for $15 \mathrm{~min}$ and cool down to room temp. Proceed to real-

532 time qPCR with the appropriate primer set and SYBR mix of your choice. Table 2 includes primer sets

533 for several genes that have been tested in MCF7, MDA MB-231 and HEK293 cell lines. However, depending on your experimental objectives and models, you may require a different set of controls.

PAUSE POINT: The cDNA samples can be stored at $-20^{\circ} \mathrm{C}$ long term.

536

46) Make a master mix with the appropriate primer set. Typically, we suggest the use of two to three

537 technical replicates. Use qPCR plates or strip tubes compatible with the real-time qPCR machine. An 538 example of a single qPCR reaction is as follows: 


\begin{tabular}{lll}
\hline Component & Amount $(\mu \mathrm{L})$ & Final concentration in RT reaction \\
\hline forward primer $(10 \mu \mathrm{M})$ & 0.5 & $500 \mathrm{nM}$ \\
forward primer $(10 \mu \mathrm{M})$ & 0.5 & $500 \mathrm{nM}$ \\
2 X SYBR mix & 5 & $1 \mathrm{X}$ \\
PCR-grade $\mathrm{H}_{2} \mathrm{O}$ & 3 & - \\
G4RP RT sample (add last) & 1 & varies \\
\hline Total & 10 & \\
\hline
\end{tabular}

540

541 47) Run the real-time qPCR using the default amplification protocol for your instrument. It should

542 typically take around 20-30 cycles to reach exponential phase ( $2-3$ hours).

543 48) Normalization is performed by calculating the percentage of G4RP or biotin control sample against

544 its respective input control using the following formula:

$$
\text { G4RP } q P C R \text { signal }=5 *\left(2^{\text {Average } \left.\left(\mathrm{Cq}_{\text {input }}\right)-\mathrm{Cq}_{G 4 R P \text { or biotin }}\right)}\right.
$$

545

546

547

548

549

550

551

552

553

554

The G4RP qPCR signal is expressed as \% of total amount of input going through G4RP that is effectively captured by BioTASQ. For each technical replicate, find the difference between the average of the $\mathrm{Cq}$ input and the individual technical replicate. Then, multiply by two to power of the previously calculated value (difference in the Cq values) by 5 (due to using $5 \%$ of the total input for normalization purposes).

\section{? TROUBLESHOOTING}

\section{Table 2. PCR primer sequences for G4RP-qPCR}

\begin{tabular}{|l|l|l|}
\hline Gene & Forward Primer Sequence $\left(5^{\prime}-3^{\prime}\right)$ & Reverse Primer Sequence $\left(5^{\prime}-3^{\prime}\right)$ \\
\hline NRAS & ATGACTGAGTACAAACTGGTGGT & CATGTATTGGTCTCTCATGGCAC \\
\hline VEGFA & CCTTGCCTTGCTGCTCTACC & AGATGTCCACCAGGGTCTCG \\
\hline MALAT1 & AAAGCAAGGTCTCCCCACAAG & GGTCTGTGCTAGATCAAAAGGCA \\
\hline
\end{tabular}

\section{Ribo-depletion and Library Preparation (TIMING: 6-8 h)}

49) Thaw the remaining TRIZOL-purified RNA samples (biotin-control, G4RP, and input; from step 36) that have been validated successfully with RT-qPCR (steps 37-48) on ice. 
50) It is recommended to have an additional column purification step before RNA-seq library preparation to remove any potential residual contamination (e.g. phenol, guanidium salt, etc.) and DNA contaminant. We recommend using the Qiagen RNeasy Plus Mini Kit and following the manufacturer's protocol. Elute at the low volume $(<25 \mu \mathrm{L})$ in RNAse-free water. Quantify RNA for concentration using Qubit fluorometer.

51) For library preparation, use the Illumina TruSeq RNA Library prep kit (with Ribo-Zero) following manufacturer's protocol. We recommend a minimum RNA input of $>50 \mathrm{ng}$ for the library preparation process. To minimize PCR bias, higher concentration (>200 ng) is preferred if sufficient input material is available. Briefly, the steps are as follows:

- Deplete rRNA using Ribo-Zero oligos and beads.

- Thermally fragment RNA briefly at 4 min.

- Synthesize the first-strand of cDNA followed by the second cDNA strand.

- Adenylate 3' ends and ligate adapters.

- Enrich DNA fragments by PCR amplification. Use the minimum number of PCR cycles if possible (5-7 cycles).

- Quality-check and quantify library using the BioAnalyzer or equivalent methods.

CRITICAL STEP: If possible, use a higher amount (200-1000 ng) of input to improve library quality and reduce PCR cycles. G4 sequences may be sensitive to PCR by inhibiting polymerase processivity and could be underrepresented after a higher number of cycles. If the input is too low for individual samples, it is recommended to pool multiple replicate samples together.

CRITICAL STEP: The fragmentation step can be modified depending on the fragment size. Due to the sonication step earlier, the average length of RNA fragments will be reduced. To avoid over- 
$578 \quad$ min of thermal fragmentation.

579 52) Pool sequencing libraries at equivalent proportion and sequence on a HiSeq, NextSeq or NovaSeq 580 platform using pair-end and read length of 75bp or higher. We recommend the sequencing depth of 581 each sample to be 15-20 million reads.

\section{Sequencing Bioinformatics analyses TIMING: varies}

583 CRITICAL An overview of the G4RP-seq analysis steps is depicted in Fig. 2b. For investigators who are less experienced with bioinformatics or lack a local workstation computer (minimum requirement: $>8$ core processor, >32 GB memory, >3 TB hard drive) performing data analysis through a remote Galaxy server ${ }^{44}$

586 (usegalaxy.org), which contains all the required bioinformatics packages, is highly recommended.

53) Quality-check raw FASTQ file using FASTQC and trim reads using Trimmomatic (38) (or equivalent read-trimming tool) with default settings.

54) Align reads to the target genome (e.g. human genome hg19 or hg38 assembly) using HISAT2 (39) using default settings. The output file should be formatted as the compressed binary version of sequence alignment files (BAM format). Integrative Genome Viewer (IGV) (40) can then be used to visualize these alignments. To load in IGV, index files will need to be generated from igvtools for each BAM file.

55) Prepare and download a gene annotation file (in GTF format) from UCSC. This can be accessed at http://genome.ucsc.edu/cgi-bin/hgTables . Make sure to choose the right genome and assembly version. Choose "Genes and Gene Predictions" for the group and "NCBI RefSeq" in the track. To use gene symbols as an attribute of interest, choose "refflat" for the table. The parameters may be changed depending on what attributes you want to be listed. Select "genome" for region and GTF as 
600

601

602

603

604

605

606

607

608

609

610

611

612

613

614

615

616

617

Steps 2-8, Crosslink: 1-2 hours (depending on the number of samples)

618 Steps 9-11, Sonication: 1-2.5 hours (depending on the number of samples)

619

620 differential expression analysis. score. It is important to note that all subsequent comparisons are relative measures. threshold can differ depending on the quality and depth of sequencing.

\section{TIMING} culturing experimental setup)

Steps 12-21, Binding and washing: overnight +4 hours

Step 22-36, RNA purification: 2 hours

56) Count features and annotate the aligned reads using HTSeq-count (41) with the prepared GTF file. Use "Union" mode and set values as follows: feature type=exon, ID attribute=gene_id. Depending on the library prep kit used, you can set the strandedness mode either "stranded" or "nonstranded." The "stranded" setting would keep data on the directionality of the transcript.

57) Use the raw count output from HTSeq-count as input for DESeq2 (42) for normalization and

58) Run DESeq2 for the BioTASQ sample vs input control for each treatment condition to generate relative BioTASQ enrichment scores (ES), which are log fold change readout between the test conditions for each transcript. The gene transcripts can be ranked according to their enrichment

59) Compare the enrichment scores between conditions to quantify ligand-induced changes in G4 RNA structures. The enrichment score change ( $\triangle \mathrm{ES})$ is calculated as follows: ES (treated) - ES (untreated).

60) Using Excel, filter transcripts by counts (as a measure of RNA abundance) and fold change. The filter

Step 1, Cell culture phase (including seeding and treatment): 2 days to 1 week (depending on cell 
622 Step 49-51, Ribodepletion and library preparation: 6-8 hours

623 Step 52-60, Sequencing and bioinformatics - varies (depending on sequencing queues and

624 computational power)

\section{TROUBLESHOOTING}

628 Please refer to Table 3 for advice on troubleshooting.

\begin{tabular}{|c|c|c|c|}
\hline \multicolumn{4}{|c|}{ Table 3. Troubleshooting table } \\
\hline Step & Problem & Possible Reason & Solution \\
\hline 9 & $\begin{array}{l}\text { Cells are too } \\
\text { clumpy and } \\
\text { difficult to } \\
\text { resuspend } \\
\end{array}$ & $\begin{array}{l}\text { Freezing after } \\
\text { formaldehyde may } \\
\text { cause clumping }\end{array}$ & $\begin{array}{l}\text { Do not freeze down pellet and directly } \\
\text { proceed to the sonication step. }\end{array}$ \\
\hline \multirow{3}{*}{10} & $\begin{array}{l}\text { No bands } \\
\text { corresponding to } \\
\text { purified RNA } \\
\text { from sonication } \\
\text { check fraction } \\
\text { visible on gel }\end{array}$ & $\begin{array}{l}\text { Crosslink reversal is } \\
\text { insufficient }\end{array}$ & $\begin{array}{l}\text { Increase duration of the crosslinking } \\
\text { reversal step to } 2 \mathrm{~h} \text {. }\end{array}$ \\
\hline & \multirow{2}{*}{$\begin{array}{l}\text { Either faint bands } \\
\text { or bands with } \\
\text { apparently high } \\
\text { molecular weight } \\
\text { observed in } \\
\text { purified RNA of } \\
\text { sonication check } \\
\text { fraction }\end{array}$} & $\begin{array}{l}\text { Cells not sonicated } \\
\text { properly. }\end{array}$ & $\begin{array}{l}\text { Reoptimize the sonication step. } \\
\text { Increase sonication duration. }\end{array}$ \\
\hline & & $\begin{array}{l}\text { Cellular components } \\
\text { not released into the } \\
\text { supernatant }\end{array}$ & $\begin{array}{l}\text { Add } 0.1 \%(\mathrm{wt} / \mathrm{vol}) \text { SDS to resuspended cells } \\
\text { before sonication }\end{array}$ \\
\hline 36 & $\begin{array}{l}\text { Low } A 260 / 280 \\
\text { ratio for RNA }\end{array}$ & $\begin{array}{l}\text { Contamination from } \\
\text { TRIZOL components } \\
\text { (e.g. Phenol), protein } \\
\text { or DNA. }\end{array}$ & $\begin{array}{l}\text { Wash twice, instead of once, with ethanol } \\
\text { during the TRIZOL extraction. This will } \\
\text { normally not impact qPCR quantification. } \\
\text { Perform an additional column purification } \\
\text { on RNA before sequencing library } \\
\text { preparation. }\end{array}$ \\
\hline
\end{tabular}




\begin{tabular}{|c|c|c|c|}
\hline & \multirow{4}{*}{$\begin{array}{l}\text { Low RNA yield of } \\
\text { all extracted } \\
\text { samples including } \\
\text { input control }\end{array}$} & $\begin{array}{l}\text { Cells not sonicated } \\
\text { properly; cellular } \\
\text { components not } \\
\text { released into the } \\
\text { supernatant. }\end{array}$ & $\begin{array}{l}\text { Reoptimize the sonication step. Increase } \\
\text { sonication duration. Adding } 0.1 \% \text { SDS to } \\
\text { resuspended cells before sonication may } \\
\text { also help. }\end{array}$ \\
\hline & & RNAse contamination & $\begin{array}{l}\text { Remake new buffers and ensure no RNase } \\
\text { contamination is present. } \\
\text { Add in fresh RNAse inhibitors in every new } \\
\text { experiment. }\end{array}$ \\
\hline & & $\begin{array}{l}\text { Problem with TRIZOL } \\
\text { RNA purification }\end{array}$ & $\begin{array}{l}\text { Check reagents used for RNA purification } \\
\text { (i.e. TRIZOL, chloroform, isopropanol, } \\
\text { ethanol). Change to fresh reagents. }\end{array}$ \\
\hline & & $\begin{array}{l}\text { Insufficient reversal of } \\
\text { crosslinking leading to } \\
\text { loss of RNA to RNPs } \\
\text { during TRIZOL step }\end{array}$ & $\begin{array}{l}\text { Increase duration of the crosslinking } \\
\text { reversal step to } 2 \mathrm{~h} \text {. }\end{array}$ \\
\hline \multirow{5}{*}{48} & \multirow{2}{*}{$\begin{array}{l}\text { High signal in } \\
\text { biotin control }\end{array}$} & $\begin{array}{l}\text { Concentration of } \\
\text { streptavidin beads too } \\
\text { high }\end{array}$ & $\begin{array}{l}\text { Add lower amounts of beads } \\
\text { Optimize pull-down by testing different } \\
\text { amounts of beads at the lower range (20- } \\
60 \mu \mathrm{g})\end{array}$ \\
\hline & & $\begin{array}{l}\text { Input too high due to } \\
\text { too many cells being } \\
\text { used which reduces } \\
\text { signal-to-background } \\
\text { ratio }\end{array}$ & $\begin{array}{l}\text { Decrease number of cells for sonication or } \\
\text { dilute cells in higher volume of shearing } \\
\text { buffer prior to sonication }\end{array}$ \\
\hline & \multirow{3}{*}{$\begin{array}{l}\text { Lower } \\
\text { enrichment of } \\
\text { BioTASQ sample } \\
\text { as detected by } \\
\text { RT-qPCR (G4RP } \\
\text { qPCR signal is } \\
<0.5 \% \text { ) }\end{array}$} & $\begin{array}{l}\text { Incorrect } \\
\text { concentration of } \\
\text { BioTASQ and beads } \\
\text { are used }\end{array}$ & $\begin{array}{l}\text { Confirm that the stock concentrations are } \\
\text { correct. Remake stock concentration if } \\
\text { uncertain. }\end{array}$ \\
\hline & & $\begin{array}{l}\text { Insufficient amounts } \\
\text { of beads }\end{array}$ & $\begin{array}{l}\text { Increase the amounts of beads; optimize } \\
\text { pull-down using different amount of beads } \\
\text { at the higher range }(50-250 \mu \mathrm{g})\end{array}$ \\
\hline & & $\begin{array}{l}\text { Over crosslinking } \\
\text { leading to loss of } \\
\text { accessibility to the G4 } \\
\text { epitopes }\end{array}$ & $\begin{array}{l}\text { Reduce crosslinking duration; it should } \\
\text { never exceed } 10 \text { min. } \\
\text { Some formaldehyde contains additives } \\
\text { (e.g. methanol) may increase cell } \\
\text { membrane permeability and crosslinking } \\
\text { efficiency, consider using fresh } \\
\text { formaldehyde without additives. Make } \\
\text { fresh glycine to quench effectively. Slightly } \\
\text { increase glycine concentration. }\end{array}$ \\
\hline
\end{tabular}




\begin{tabular}{|c|c|c|}
\hline & RNAse contamination & $\begin{array}{l}\text { Remake new buffers and ensure no RNase } \\
\text { contamination is present. } \\
\text { Add in fresh RNAse inhibitors in every new } \\
\text { experiment. }\end{array}$ \\
\hline \multirow[b]{2}{*}{$\begin{array}{l}\text { Low ligand- } \\
\text { induced change } \\
\text { detected }\end{array}$} & $\begin{array}{l}\text { Under crosslinking } \\
\text { leading to bias } \\
\text { towards BioTASQ } \\
\text { stabilization }\end{array}$ & $\begin{array}{l}\text { Increase crosslinking duration in the range } \\
\text { between } 5 \text { min to } 10 \mathrm{~min} \text {. } \\
\text { Keep samples on ice or } 4^{\circ} \mathrm{C} \text { after } \\
\text { crosslinking. }\end{array}$ \\
\hline & $\begin{array}{l}\text { Treatment with an } \\
\text { insufficient dose of G4 } \\
\text { ligand }\end{array}$ & $\begin{array}{l}\text { Cell lines can exhibit varying degrees of } \\
\text { sensitivity to G4 ligands. Perform a dose- } \\
\text { response curve to profile the cytotoxicity } \\
\text { of a specific G4 ligand in a specific cell line } \\
\text { and chose a subtoxic dose. Reconsider the } \\
\text { treatment duration. Typical timepoints } \\
\text { include } 24 \mathrm{~h} \text { and } 48 \mathrm{~h} \text {. Depending on the } \\
\text { stability of the ligand, new stocks may } \\
\text { need to be produced or purchased. }\end{array}$ \\
\hline $\begin{array}{l}\text { Low qPCR signal } \\
\text { (high Ct values; } \\
>35 \text { cycles) for all } \\
\text { samples }\end{array}$ & $\begin{array}{l}\text { Problems with reverse } \\
\text { transcription and/or } \\
\text { qPCR }\end{array}$ & $\begin{array}{l}\text { Check reagents for RT-qPCR. } \\
\text { Run a positive control with a different } \\
\text { confirmed sample. }\end{array}$ \\
\hline
\end{tabular}
ANTICIPATED RESULTS

\section{Sonication check}

634 Due to the different sonication techniques used by different laboratory groups, it is advised that a

635 sonication check be performed using different sonication conditions. For example, for the Covaris m220

636 Ultrasonicator, we divided a crosslinked sample and performed parallel comparisons between different

637 sonication conditions (sonication duration: $0 \mathrm{~min}, 2 \mathrm{~min}$ and $4 \mathrm{~min}$ ) under the same settings. Sonicated

638 samples can be heated for $1 \mathrm{~h}$ to reverse crosslinks, and the RNA can be extracted using TRIZOI or RNA

639 column purifications. The purified RNA can then be observed on an RNA bleach gel stained with SYBR 
640 green nucleic acid gel stain ${ }^{43}$. As depicted in Fig. 2a, absence of sonication would result in an inefficient

641 release of RNA from crosslinked material. Note that crosslink reversal is inefficient in unsonicated

642 material and thus would result in a loss of extracted RNA, as shown by the lack of RNA band on the gel

643 for the 0 min condition. Generally, a sonication duration of $2-4 \mathrm{~min}$ is sufficient, yielding a range of

644 bands between 200-800 nt. Longer sonication duration leads to a shorter average length of RNA

645 fragments, as seen by the shifting of the median band length between the 2 and 4 minutes of sonication

646 conditions. It is important to note that, while longer sonication may help increase resolution, it may also

647 disrupt some interactions. Thus, a balanced approach is required to prevent under- or over-sonication.

\section{RNA yield from G4RP}

649 After TRIZOL-purification, the purified RNA can be quantified using Nanodrop or other comparable 650 methods. A lower A260/280 ratio $(<1.8)$ is usually indicative of contamination from TRIZOL extraction.

651 However, A260/280 value may not be reliable if the sample concentration is too low. In that case, a

652 more sensitive method, such as Qubit, may be employed. Typically, the concentration of the 5\% input 653 sample is around $100 \mathrm{ng} / \mu \mathrm{L}$ (with a $30 \mu \mathrm{L}$ yield $=3 \mu \mathrm{g}$ ). The concentration of the BioTASQ-enriched 654 sample varies around 100-200 ng/ $\mu \mathrm{L}(30 \mu \mathrm{L}$ yield of 3-6 $\mu \mathrm{g})$. The concentration of the biotin control 655 sample is much lower at $\sim 50 \mathrm{ng} / \mu \mathrm{L}(30 \mu \mathrm{L}$ yield of $1.5 \mu \mathrm{g})$, as the biotin control consists mostly of non656 specific rRNA binding to the beads. Regardless of purity or concentration, we highly recommend column 657 purification before further processing (i.e. ribodepletion and library preparation) for RNA-seq.

\section{G4RP-qPCR quantification}

RT-qPCR quantification of the G4RP samples typically yields high signal-to-background ratios (>20 fold 660 enrichment) when comparing \% input yield from BioTASQ versus the biotin control sample (Fig. 2b). 661 Ligand-induced change ranges from 2-fold to as high as 12-fold, depending on the RNA target and G4 662 ligand used. 
664 After processing the raw sequencing files through a series of bioinformatics tools (Fig. 3a), the

665 differential expression values (output from DESeq2) derived from comparing the BioTASQ sample with

666 its corresponding input control, are used to determine the BioTASQ enrichment score. A quick indicator 667 of a successful G4RP-seq is to rank the transcripts by enrichment score and check for an increase in GC 668 content. At baseline levels (derived from samples not treated with a G4 ligand), the enrichment score is 669 expected to be positively correlated with the GC\% of the gene transcript (Fig.3b). Signals of aligned 670 reads can be visualized using IGV (Fig. 3c). The biotin control is expected to show negligible levels with 671 reads primarily aligned to rRNA regions. By comparing the BioTASQ signal with that of the input control, 672 the relative level of BioTASQ interaction with the target can be elucidated (Fig. 3c). An example of a high 673 G4-ligand-inducible target is the long non-coding RNA, MALAT1. The raw signals show much higher 674 alignments in the G4-ligand-treated samples compared to that of the untreated sample.

Figure 1. Overview of G4RP. a, Chemical structure of BioTASQ in its open (in absence of a G4 target) and 679 closed conformations (in the presence of a G4 target). b, Schematics of the G4RP workflow. 1) Cells are 680 cultured in $10 \mathrm{~cm}$ culture dishes. If required, cells may be treated with G4 ligands at this stage to 681 increase global G4 levels. 2) Cells are crosslinked using formaldehyde. 3) Cells are harvested by scraping 682 and sonicated using an ultrasonicator. 4) BioTASQ is added to the sonicate. 5) Streptavidin beads are 683 added. 6) Beads are washed multiple times. 7) Beads are heated to reverse the crosslinks. 8) TRIZOL is 684 added to the sample, and the RNA fraction is purified. 9) Reverse-transcription is performed on the RNA 685 sample before quantification using real-time quantitative PCR. 
Figure 2. Expected results from G4RP. a, An example of an bleach RNA gel (1.5\% agarose $w / v, 1 \%$

687 bleach, v/v, 1X TAE; post-staining with SYBR Green Gel Stain) for crosslinked samples that have undergone different durations of sonication (0, 2, 4 min). b, (Top) G4RP-qPCR signal of BioTASQ vs biotin control for RNA transcript targets, VEGFA and NRAS. Multiple t-test was performed. (Bottom) G4 ligand

690 (BRACO-19 $9^{45}$ and RHPS4 ${ }^{46}$ )-induced changes in the G4RP-qPCR signals for targets, VEGFA, NRAS and 691 MALAT1. One-way ANOVA with Dunnett's multiple correction was performed for each gene to compare each condition against its respective non-treated control. Each point represents a biological replicate.

693 Three biological replicates were used to quantify the means. Error bars represent SEM. These data are 694 derived from a previous published work $^{16}$.

695 Figure 3. Expected results from G4RP-seq. a, Schematic of the G4RP-seq bioinformatics analyses. b, 696 Linear regression plot comparing the BioTASQ Enrichment Score with GC content of respective gene 697 transcripts at baseline (derived from untreated sample). Each dot represents a gene transcript $(n=5083)$.

698 Analysis shows a significant non-zero relationship with a positive slope $(p<0.0001)$ and a moderate 699 positive correlation ( $R=0.47)$. $c$, Signal of aligned sequencing reads in the MALAT1 region for (Left) biotin control, BioTASQ in untreated sample, BioTASQ in BRACO-19-treated sample and BioTASQ in RHPS4-

701 treated sample and (Right) the corresponding input controls. The G4RP-seq datasets used are available 702 under the accession number GSE112898.

\section{DATA AVAILABILITY}

All relevant data are available upon request. The G4RP-qPCR dataset (Fig. 2) is publicly available on

705 FigShare (https://doi.org/10.6084/m9.figshare.16684870). The raw sequencing data used in the 706 examples shown in Fig. 3 in this protocol are publicly available and accessible at GSE112898. 
709 This work is supported by the Research Reinvestment Funds from the University of British Columbia and 710 Agence Nationale de la Recherche (ANR-17-CE17-0010-01). Pauline Lejault is warmly acknowledged for 711 her critical analysis of the G4RP protocol and of the manuscript.

\section{AUTHOR CONTRIBTUTIONS}

713 S.Y.Y., D.M. and J.M.Y.W designed the experiments. S.Y.Y. and J.M.Y.W. wrote the manuscript with 714 inputs from D.M.

\section{COMPETING INTERESTS}

716 The authors declare no competing interests.

\section{REFERENCES}

718 1. Burge, S., Parkinson, G. N., Hazel, P., Todd, A. K. \& Neidle, S. Quadruplex DNA: sequence, topology and structure. Nucleic Acids Research 34, 5402-5415 (2006).

720

2. Spiegel, J., Adhikari, S. \& Balasubramanian, S. The Structure and Function of DNA G-

721 Quadruplexes. Trends in Chemistry 2, 123-136 (2020).

722 3. Rhodes, D. \& Lipps, H. J. G-quadruplexes and their regulatory roles in biology. Nucleic Acids $723 \quad$ Research 43, 8627-8637 (2015).

724 4. Fay, M. M., Lyons, S. M. \& Ivanov, P. RNA G-Quadruplexes in Biology: Principles and Molecular 725 Mechanisms. Journal of Molecular Biology 429, 2127-2147 (2017).

726 5. Marsico, G. et al. Whole genome experimental maps of DNA G-quadruplexes in multiple 727 species. Nucleic Acids Research 47, 3862-3874 (2019).

728 6. Maizels, N. G4-associated human diseases. EMBO reports 16, 910-922 (2015). 
7. Raguseo, F., Chowdhury, S., Minard, A. \& Di Antonio, M. Chemical-biology approaches to probe DNA and RNA G-quadruplex structures in the genome. Chemical Communications 56, 1317-1324 (2020).

8. Puig Lombardi, E. \& Londoño-Vallejo, A. A guide to computational methods for G-quadruplex prediction. Nucleic Acids Research 48, 1-15 (2019).

9. Monchaud, D. Quadruplex detection in human cells. Annual Reports in Medicinal Chemistry 133-160 (2020) doi:10.1016/bs.armc.2020.04.007.

10. Kwok, C. K. \& Merrick, C. J. G-Quadruplexes: Prediction, Characterization, and Biological

11. Biffi, G., Tannahill, D., McCafferty, J. \& Balasubramanian, S. Quantitative visualization of DNA Gquadruplex structures in human cells. Nature Chemistry 5, 182-186 (2013).

12. Chambers, V. S. et al. High-throughput sequencing of DNA G-quadruplex structures in the human genome. Nature Biotechnology 33, 877-881 (2015).

13. Hänsel-Hertsch, R., Spiegel, J., Marsico, G., Tannahill, D. \& Balasubramanian, S. Genome-wide mapping of endogenous G-quadruplex DNA structures by chromatin immunoprecipitation and highthroughput sequencing. Nature Protocols 13, 551-564 (2018).

14. Zheng, K. et al. Detection of genomic G-quadruplexes in living cells using a small artificial protein. Nucleic Acids Research (2020) doi:10.1093/nar/gkaa841.

15. Kwok, C. K., Marsico, G., Sahakyan, A. B., Chambers, V. S. \& Balasubramanian, S. rG4-seq reveals widespread formation of G-quadruplex structures in the human transcriptome. Nature Methods 13, 841-844 (2016).

16. Yang, S. Y. et al. Transcriptome-wide identification of transient RNA G-quadruplexes in human cells. Nature Communications 9, (2018).

17. Mendoza, O., Bourdoncle, A., Boulé, J.-B., Brosh, R. M. \& Mergny, J.-L. G-quadruplexes and helicases. Nucleic Acids Research 44, 1989-2006 (2016). 
18. Varshney, D., Spiegel, J., Zyner, K., Tannahill, D. \& Balasubramanian, S. The regulation and functions of DNA and RNA G-quadruplexes. Nature Reviews Molecular Cell Biology 21, 459-474 (2020).

19. Ganser, L. R., Kelly, M. L., Herschlag, D. \& Al-Hashimi, H. M. The roles of structural dynamics in the cellular functions of RNAs. Nature Reviews Molecular Cell Biology 20, 474-489 (2019).

20. Rodriguez, R. et al. A Novel Small Molecule That Alters Shelterin Integrity and Triggers a DNADamage Response at Telomeres. Journal of the American Chemical Society 130, 15758-15759 (2008).

21. Guo, J. U. \& Bartel, D. P. RNA G-quadruplexes are globally unfolded in eukaryotic cells and depleted in bacteria. Science 353, aaf5371-aaf5371 (2016).

22. Umar, M. I., Ji, D., Chan, C.-Y. \& Kwok, C. K. G-Quadruplex-Based Fluorescent Turn-On Ligands and Aptamers: From Development to Applications. Molecules 24, 2416 (2019).

23. Stefan, L. \& Monchaud, D. Applications of guanine quartets in nanotechnology and chemical biology. Nature Reviews Chemistry 3, 650-668 (2019).

24. Haudecoeur, R., Stefan, L., Denat, F. \& Monchaud, D. A Model of Smart G-Quadruplex Ligand. Journal of the American Chemical Society 135, 550-553 (2013).

25. Laguerre, A. et al. A Twice-As-Smart Synthetic G-Quartet: PyroTASQ Is Both a Smart Quadruplex Ligand and a Smart Fluorescent Probe. Journal of the American Chemical Society 136, 12406-12414 (2014).

26. Laguerre, A. et al. Visualization of RNA-Quadruplexes in Live Cells. Journal of the American Chemical Society $137,8521-8525$ (2015).

27. Renard, I. et al. Small-molecule affinity capture of DNA/RNA quadruplexes and their identification in vitro and in vivo through the G4RP protocol. Nucleic Acids Research 47, 5502-5510 (2019).

28. Gilbert, C. \& Svejstrup, J. Q. RNA Immunoprecipitation for Determining RNA-Protein Associations In Vivo. Current Protocols in Molecular Biology 75, 27.4.1-27.4.11 (2006). 
29. Müller, S., Kumari, S., Rodriguez, R. \& Balasubramanian, S. Small-molecule-mediated G-quadruplex isolation from human cells. Nature Chemistry 2, 1095-1098 (2010).

30. Neidle, S. Quadruplex Nucleic Acids as Novel Therapeutic Targets. Journal of Medicinal Chemistry 59, 5987-6011 (2016).

31. Kubota, M., Tran, C. \& Spitale, R. C. Progress and challenges for chemical probing of RNA structure inside living cells. Nature Chemical Biology 11, 933-941 (2015).

32. Sharma, E., Sterne-Weiler, T., O'Hanlon, D. \& Blencowe, B. J. Global Mapping of Human RNA-RNA Interactions. Molecular Cell 62, 618-626 (2016).

33. Nguyen, T. C. et al. Mapping RNA-RNA interactome and RNA structure in vivo by MARIO. Nature Communications 7, (2016).

34. Aw, J. G. A. et al. In Vivo Mapping of Eukaryotic RNA Interactomes Reveals Principles of HigherOrder Organization and Regulation. Molecular Cell 62, 603-617 (2016).

35. Lu, Z. et al. RNA Duplex Map in Living Cells Reveals Higher-Order Transcriptome Structure. Cell 165, 1267-1279 (2016).

36. Ruggiero, E., \& Richter, S. N. G-quadruplexes and G-quadruplex ligands: targets and tools in antiviral therapy. Nucleic acids research, 46, 3270-3283 (2018).

37. Saranathan, N., \& Vivekanandan, P. G-quadruplexes: more than just a kink in microbial genomes. Trends in microbiology, 27, 148-163 (2019).

38. Bolger, A. M., Lohse, M. \& Usadel, B. Trimmomatic: a flexible trimmer for Illumina sequence data. Bioinformatics 30, 2114-2120 (2014).

39. Kim, D., Langmead, B. \& Salzberg, S. L. HISAT: a fast spliced aligner with low memory requirements. Nature Methods 12, 357-360 (2015).

40. Thorvaldsdottir, H., Robinson, J. T. \& Mesirov, J. P. Integrative Genomics Viewer (IGV): highperformance genomics data visualization and exploration. Briefings in Bioinformatics 14, 178-192 (2012). 
802 41. Anders, S., Pyl, P. T. \& Huber, W. HTSeq--a Python framework to work with high-throughput 803 sequencing data. Bioinformatics 31, 166-169 (2014).

804 42. Love, M. I., Huber, W. \& Anders, S. Moderated estimation of fold change and dispersion for RNA-seq 805 data with DESeq2. Genome Biology 15, (2014).

806 43. Aranda, P. S., LaJoie, D. M. \& Jorcyk, C. L. Bleach gel: A simple agarose gel for analyzing RNA 807 quality. ELECTROPHORESIS 33, 366-369 (2012).

808 44. Goecks, J., Nekrutenko, A., Taylor, J. \& Galaxy Team, T. Galaxy: a comprehensive approach for 809 supporting accessible, reproducible, and transparent computational research in the life 810 sciences. Genome Biology 11, R86 (2010).

811 45. Read, M. et al. Structure-based design of selective and potent G quadruplex-mediated telomerase inhibitors. Proceedings of the National Academy of Sciences 98, 4844-4849 (2001).

813 46. Heald, R. A. et al. Antitumor Polycyclic Acridines. 8.1Synthesis and Telomerase-Inhibitory Activity of 814 Methylated Pentacyclic Acridinium Salts. Journal of Medicinal Chemistry 45, 590-597 (2002). 

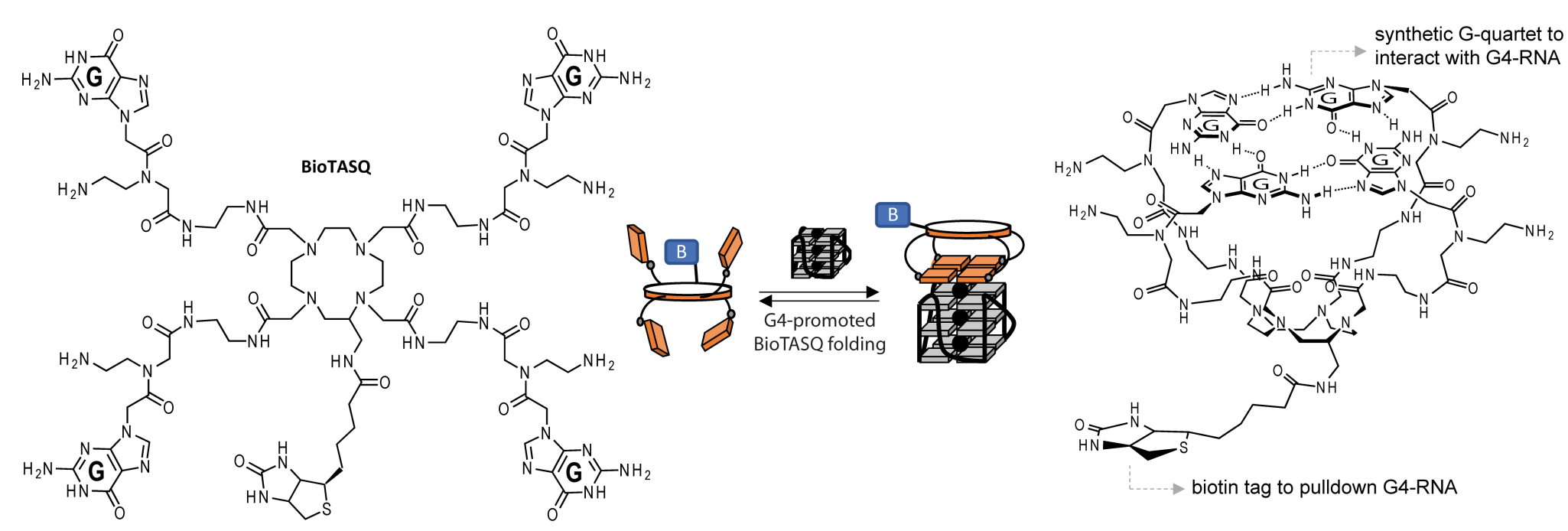

B

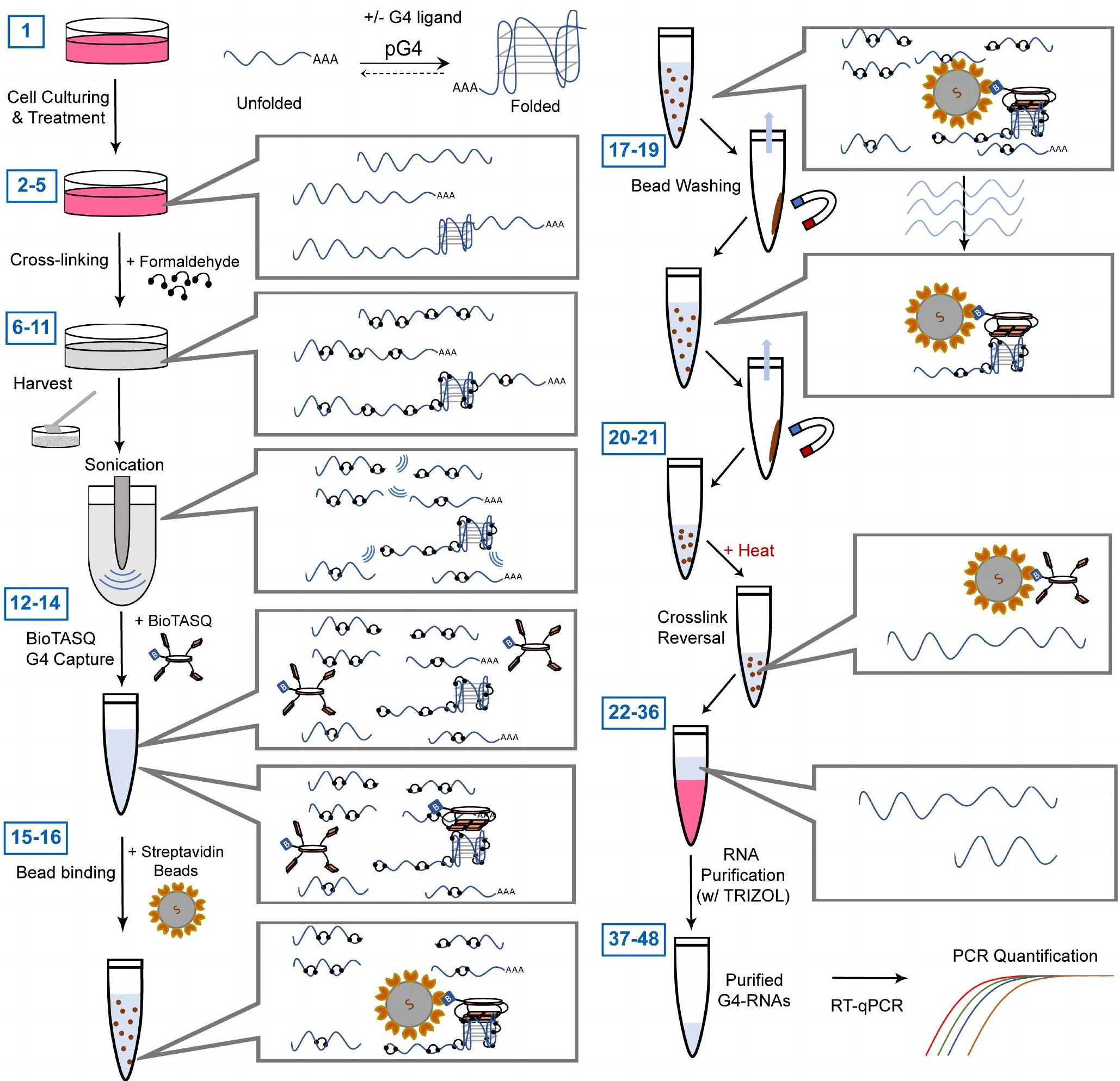




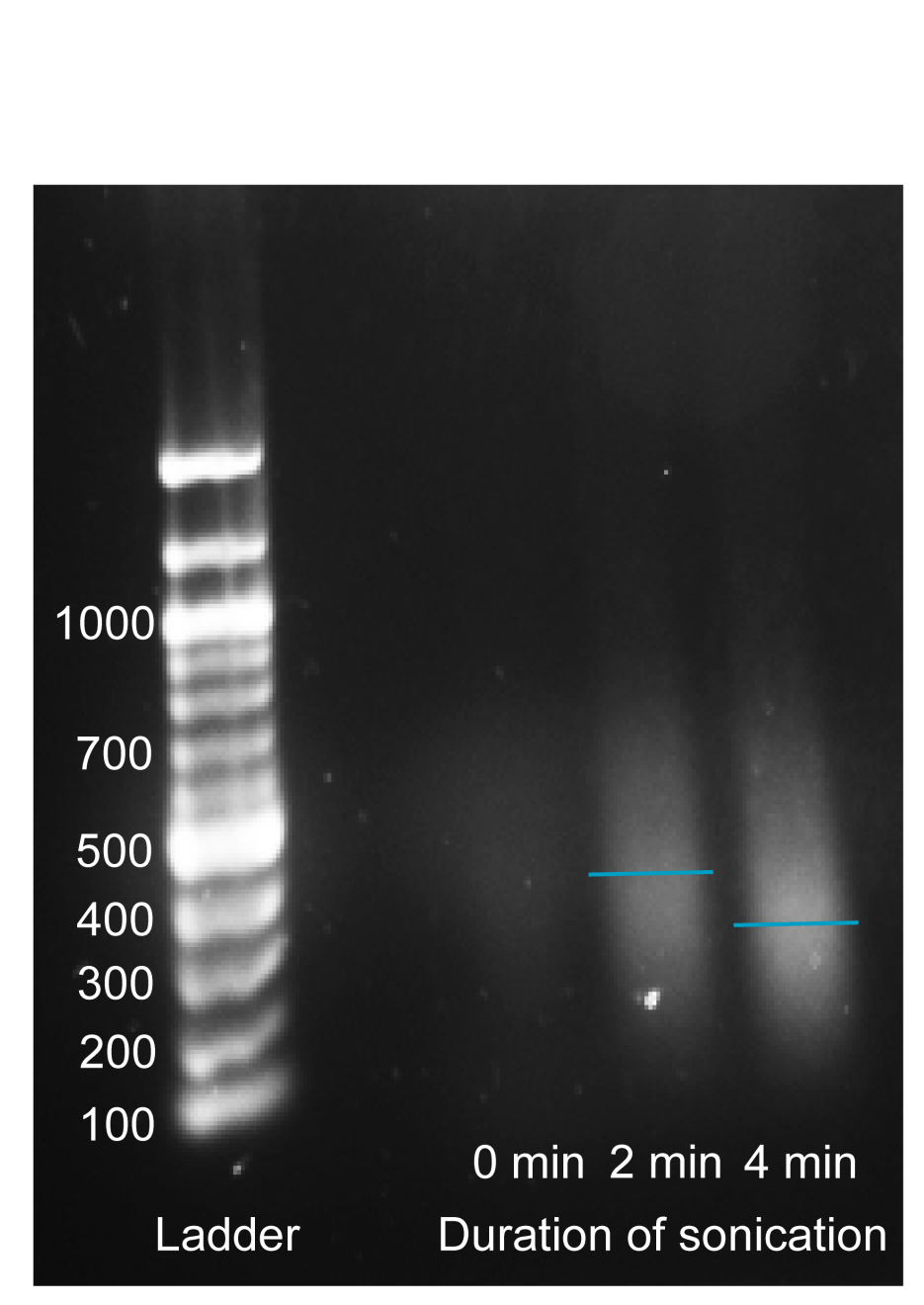

B
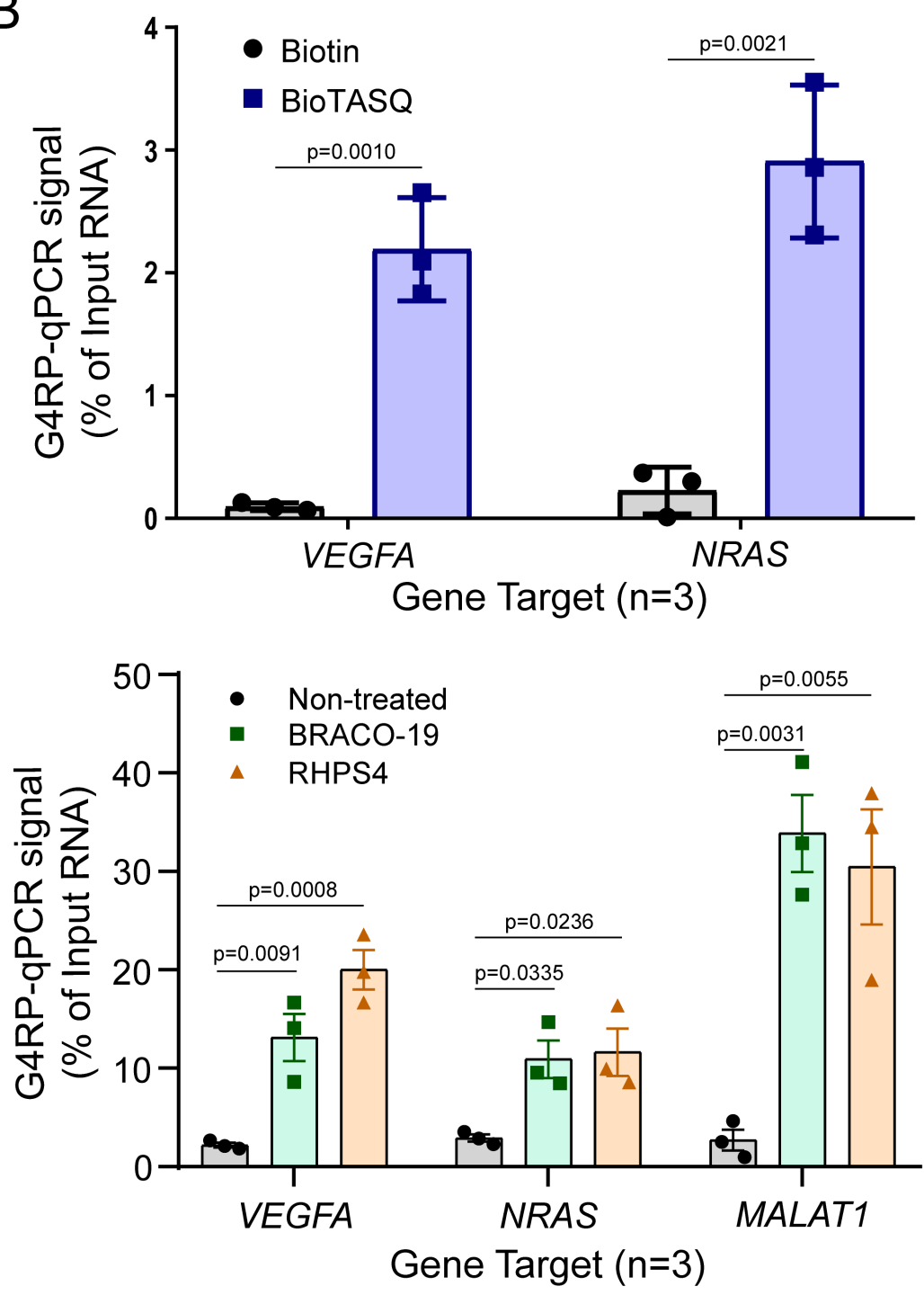

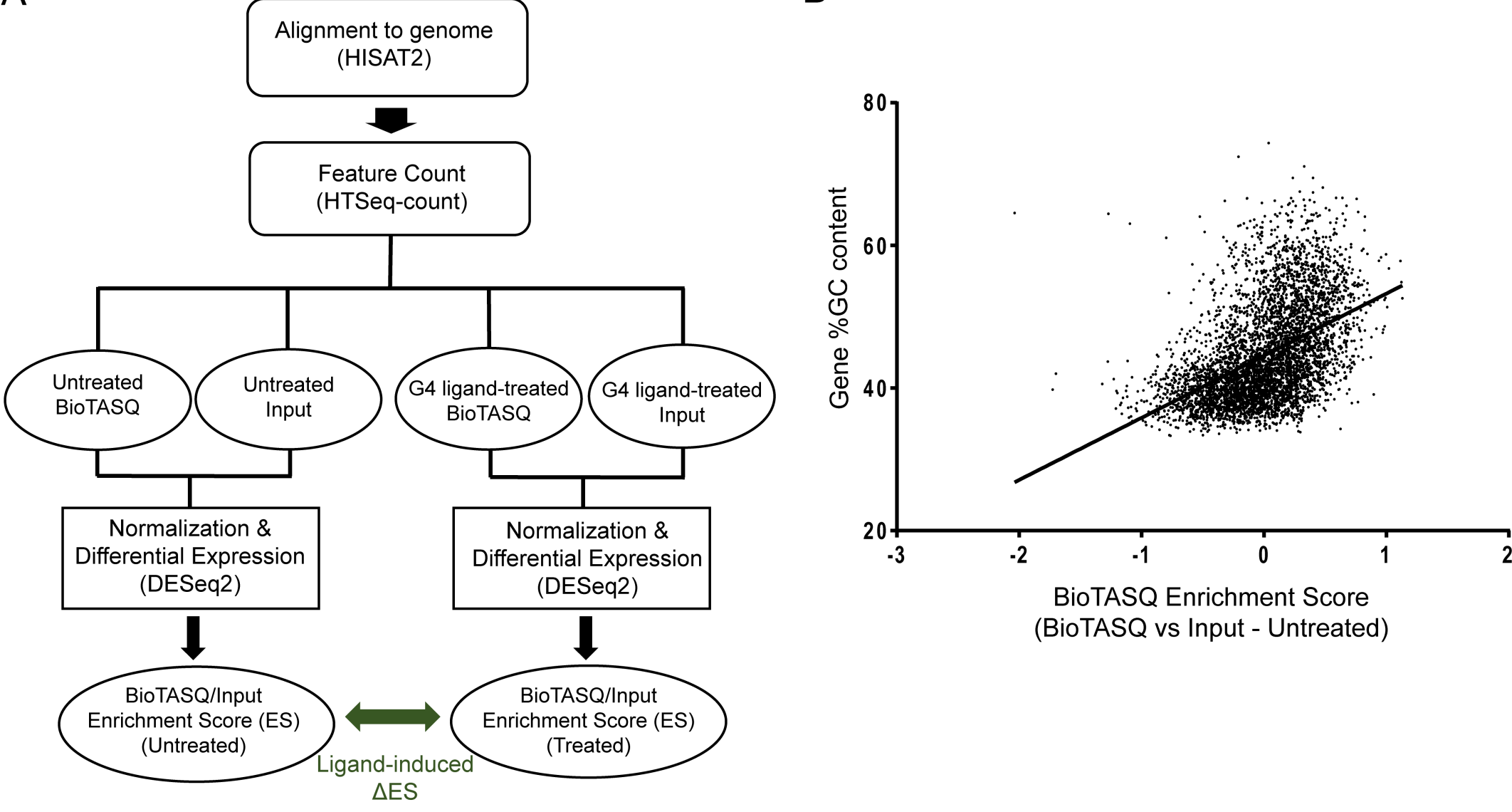

BioTASQ Enrichment Score (BioTASQ vs Input - Untreated)

C

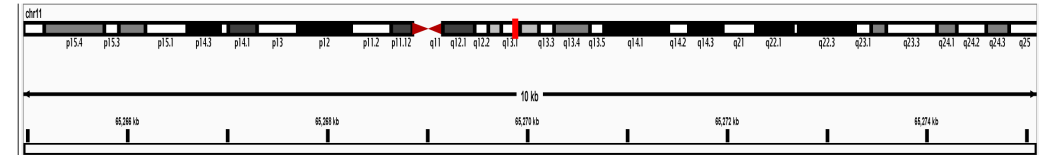

Biotin control

[0-20000]

BioTASQ (Untreated)

[0-20000]

BioTASQ (BRACO-19)

[0-20000]

BioTASQ (RHPS4)

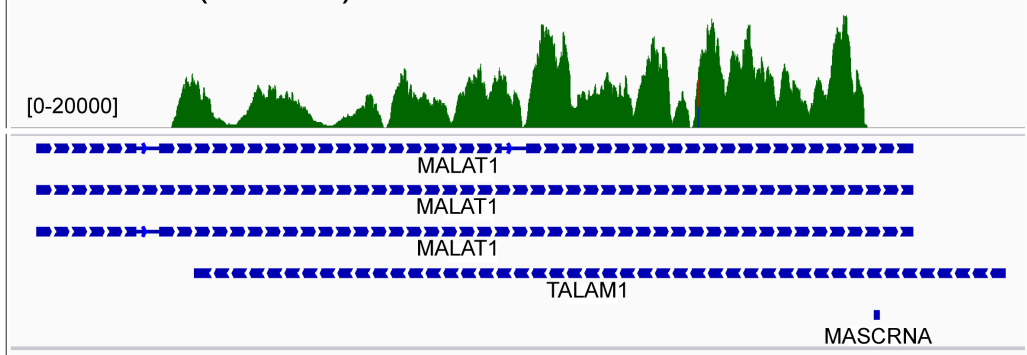

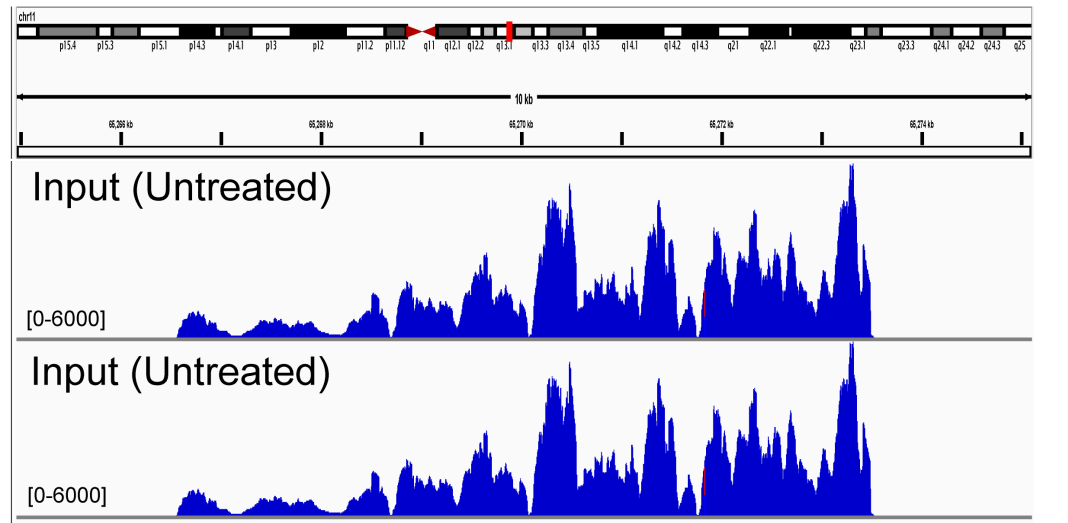

Input (BRACO-19)

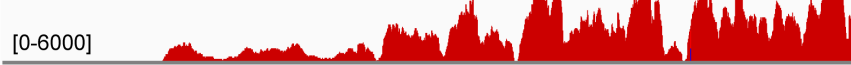

Input (RHPS4)

[0-6000]

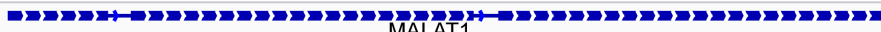

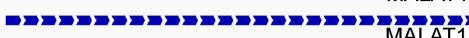

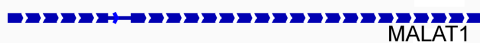

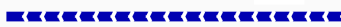

